\section{AB019. Response to tofacitinib in a case of refractory TIF- 1 positive amyopathic dermatomyositis with arthritis}

\author{
Sion Ward Jasmine ${ }^{1}$, Deepali Sen ${ }^{2}$, \\ Heather Anna Jones ${ }^{3}$
}

${ }^{1}$ Division of Dermatology, Washington University in St. Louis/BarnesJewish Consortium, St. Louis, MO, USA; ${ }^{2}$ Division of Rheumatology, ${ }^{3}$ Division of Dermatology, Washington University in St. Louis, St. Louis, MO, USA

Correspondence to: Heather Anna Jones, MD. Division of Dermatology, Washington University in Saint Louis, 660 South Euclid, Saint Louis, 63110 MO, USA. Email: heather.jones@wustl.edu.

\begin{abstract}
A 47-year-old woman with a previous diagnosis of undifferentiated connective tissue disease presented to our clinic for evaluation of rash and joint pains. She had a significant history of severe fatigue, musculoskeletal and joint pains. She described her joint pain as constant, stating it severely impacted her activities of daily living, but denied muscle weakness. She was previously diagnosed with systemic lupus erythematosus (SLE), and treated unsuccessfully with low dose systemic steroids and antimalarial therapy. Upon examination, she was found to have heliotrope eruption, Gottron's sign and Gottron's papules, fulfilling EULAR/ACR classification criteria for dermatomyositis. On the myositis panel she tested positive for antibodies to TIF1 and NXP2, confirming the diagnosis. She was also found to have RF positive but CCP negative arthropathy, without evidence of radiographic erosions. She was responsive to prednisone but either skin or joint symptoms remained refractory to several steroid-sparing agents including hydroxychloroquine, mycophenolate mofetil, methotrexate, intravenous immunoglobulin and
\end{abstract}

eventually infliximab. With subsequent visits, she reported worsening of joint pain, despite improvement of cutaneous burden of disease on mycophenolate mofetil. In the setting of debilitating joint pain, she was started on tofacitinib $11 \mathrm{mg}$ PO daily in addition to hydroxychloroquine 200 mg PO BID with discontinuation of mycophenolate mofetil. After two months of treatment she reported $90 \%$ improvement in symptoms, with resolution of joint pains and no recurrences of her rash, and was able to return to baseline functional status. Teaching points: (I) overlap syndrome with dermatomyositis has been previously reported in a case report showing 19\% overlap with other connective tissue diseases, including rheumatoid arthritis; (II) the overlap of the two conditions can be extremely debilitating to patients, with few options for complete symptom resolution; (III) tofacitinib is an inhibitor of Janus kinase 1 (JAK1) and Janus kinase 3 (JAK3) and works by inhibiting JAK signaling for many pro-inflammatory cytokines. Maximizing this mechanism can be a novel approach to treating recalcitrant immune-mediated inflammatory diseases.

Keywords: Amyopathic dermatomyositis; refractory; TIF-1; JAK inhibitors

doi: 10.21037/atm.2021.AB019

Open Access Statement: This is an Open Access article distributed in accordance with the Creative Commons Attribution-NonCommercial-NoDerivs 4.0 International License (CC BY-NC-ND 4.0), which permits the noncommercial replication and distribution of the article with the strict proviso that no changes or edits are made and the original work is properly cited (including links to both the formal publication through the relevant DOI and the license). See: https://creativecommons.org/licenses/by-nc-nd/4.0/.

Cite this abstract as: Jasmine SW, Sen D, Jones HA. Response to tofacitinib in a case of refractory TIF-1 positive amyopathic dermatomyositis with arthritis. Ann Transl Med 2021;9(5):AB019. doi: 10.21037/atm.2021.AB019 